\title{
Preliminary Results in a Multi-site Empirical Study on Cross-organizational ERP Size and Effort Estimation
}

\author{
Maya Daneva \\ Dept of Computer Science, University of Twente, Enschede, The Netherlands \\ m.daneva@utwente.nl
}

\begin{abstract}
This paper reports on initial findings in an empirical study carried out with representatives of two ERP vendors, six ERP adopting organizations, four ERP implementation consulting companies, and two ERP research and advisory services firms. Our study's goal was to gain understanding of the state-of-the practice in size and effort estimation of cross-organizational ERP projects. Based on key size and effort estimation challenges identified in a previously published literature survey, we explored some difficulties, fallacies and pitfalls these organizations face. We focused on collecting empirical evidence from the participating ERP market players to assess specific facts about the state-of-the-art ERP size and effort estimation practices. Our study adopted a qualitative research method based on an asynchronous online focus group.
\end{abstract}

\section{Introduction}

Requirements specification and architecture design of Enterprise Resource Planning (ERP) solutions mostly takes place in a cross-organizational context [5]. We define cross-organizational ERP systems as information systems that consist of standard ERP software packages and automate cross-organizational process work flows and data control flows, composed of flow fragments owned by or shared among multiple companies. The packages in a cross-organizational ERP system may or may not all be shared by the participating companies; and they may each be provided by the same vendor or by different vendors, each having its own application logic, data formats, and data semantics. Cross-organizational ERP projects tend to have a very high frequency of schedule and cost overruns, quality problems, and outright cancellations [7].

In software engineering, a cost estimation problem is the problem to predict the likely amount of efforts, time, and staffing levels to build a software system [9]. Standard functional size measurement (FSM) models $[11,12,13]$ exist to quantify the functionality that the system provides to its users and to estimate how much effort and time it would take to implement this functionality. Standard FSM models approach the software cost estimation problem by computing a weighted sum of counts of userrecognizable features based primarily on the logical design of the software solution. These counts, then, serve as the key inputs to the prediction of the effort and time needed to build the system [2]. However, the standard FSM models are general solutions initially invented for tailor-made software construction and appear inadequate to the cost estimation problem in ERP implementation settings. Traditional 
software cost estimation methods perform poorly in cross-organizational ERP implementation context also because they account for factors which only partially describe this context, and they let partner companies incorporate their bias and intuition into the estimate. Even established approaches such as COCOMO [1] are not suitable to cross-organizational projects [6]. Recent studies [6,14,20] indicate that ERP implementation projects experience a shortage of proper methodologies to evaluate functional size, effort, productivity, schedule, and other cost factors. Even when FSM data exists, effort and duration for similar ERP projects have been noted to vary widely due to (i) variations in the work actually performed on the projects, (ii) variations in the work included in project measurements, and (iii) variations in compensation rates and overhead costs. Each of these three reasons can introduce variances that approach $100 \%$ [14]. Yet, without understanding the impact of these three factors, it is not possible to establish productivity averages for crossorganizational ERP implementation teams. In cross-organizational ERP context, these issues are coupled with absence of relevant metrics and historical project datasets. For example, the quantification of reuse of shared data bases and data warehouses as part of an ERP system is a key topic with no metrics at all.

A literature survey [6] we carried out in 2005-06 sketched the problem domain of cross-organizational ERP effort estimation and surveyed existing solutions. Its results were summarized in a list of 10 hypotheses which had implications for both effort estimation analysts and researchers. We used this literature survey as the theoretical foundation for the design of an empirical study which we meant to carry out with four types of organizations who were players in the ERP market.

In this paper, we present some preliminary results from our empirical study. Its overall goal is to explore the state-of-the practice in cross-organizational ERP size and effort estimation. In this study, we focused on the challenges faced by those involved in ERP estimation from the perspective of (i) ERP adopting organizations, (ii) ERP implementation consultants, and (iii) ERP vendors. We got a total of 12 representatives from these three organization types participate in the study. Their perspectives were coupled with insights collected from two representatives from ERP research and advisory firms. We adopted a qualitative research method relying on an online focus group. We, then, grouped the findings into clusters reflecting the structure of our 10 hypotheses from the literature survey [6] to present evidence referring to each hypothesis. However, we make a note, that in this paper, we do not aim at testing the hypotheses formally. Instead, our goal is to build up the "weight of evidence" [19] in support of particular propositions, where evidence is as diverse as possible. As Seaman [19] recommends, we adopt a long-term plan to use the "weight of evidence" to refine the propositions (from our literature survey) to better fit the data. Our motivation for not testing hypotheses is threefold: (a) we have no access to a statistically representative sample of organizations so that we can draw conclusions about the findings in the literature study; (b) we must run some more sophisticated processes for qualitative data analysis [18] in order to derive new knowledge out of the observations that the representatives of the participating organizations provided to us; and (c) building up evidence via qualitative research methods is as instrumental to understanding a software engineering practice as using quantitative methods is [19]. The first two reasons, labeled with (a) and (b), are constraints, which, though detracting from our contribution, do not prevent us from gaining a deeper 


\section{Preliminary Results in a Multi-site Empirical Study on Cross-organizational ERP Size}

and Effort Estimation

understanding of the real-life problems faced by ERP players. At the time of writing, to the best of the author's knowledge, very little research was published in ERP cost estimation and almost no research covered the cross-organizational ERP settings. So, this paper is a first step towards systematically getting insights into how size and effort estimation works (or does not work) in practice. It is a first step of a larger initiative [4] of conceptualizing and organizing the body of knowledge which could be relied on as the foundation for changing the ERP adopters' effort estimation process. In the remainder of this paper, Section 2 summarizes our research method, Section 3 provides clusters of results from our empirical study which address the 10 hypotheses from our earlier literature study [6], and Section 4 discusses some validity threats. Finally, Section 5 reports on the research plan we came up with based on the early results.

\section{Research Approach}

Our approach reflects the notion that the essence of an empirical study is to learn something of value by comparing what we believe to what we see in reality [18]. We set out to investigate the current practice of size and effort estimation in the prerequirements and the requirements stages of cross-organizational ERP projects. Specifically, we investigated the challenges organizations face from vendor's, ERP implementation consultant's and ERP adopter's perspective, when carrying out business case analysis and estimating functional size and effort as part of it. We adopted a qualitative research approach $[8,19]$ because (i) it best suits our research context, in which there is little previous work and context variables are hard to define and quantify, (ii) it enables an enhanced understanding of why and how aspects of a phenomenon [18], (iii) it fits the setup of explorative studies on 'in-situ' software engineering practices (and cross-organizational ERP cost estimation is of such a nature), and (iv) it is useful in assessing the potential value of future research activities [8], as it gets practitioners involved in the research process. Our qualitative approach implemented (i) an asynchronous online focus group for data collection $[10,15,17]$ and (ii) a member-checking technique [16] for data analysis. A focus group occurs when professionals are brought together to discuss a given topic, which is monitored, facilitated (if needed) and recorded by a researcher. We selected this inquisitive technique because (i) it is known for its cost-effectiveness [15], (ii) it provides ready-to-use transcribed data, (iii) it is flexible so that our group members sitting in various time zones could contribute at their most convenient time, (iv) it encourages candid interchanges and reduces issues of interviewer's effect as focus group members can not "see" each other, and (v) it allows responses that are usually lengthier than in a synchronous mode [17]. The online group comprised 14 members:

- 12 ERP solution architects practicing in Europe and North America and representing two ERP vendors, six ERP adopting organizations, and four ERP implementation consulting companies, and

- two ERP practice analysis representing two US-based ERP research and advisory companies. 
All ERP architects were in charge of cross-organizational projects that had stakeholders at locations distributed in at least two organizations. Each architect (i) had at least 3 years of experience in cross-organizational ERP RE, (ii) has been involved in the estimation of the efforts for cross-organizational projects, and (iii) has done proposals to assess the impact of specific cost drivers on specific projects in the pre-requirements or the requirements stages of their projects. The two ERP practice analysts had observed the trends in the ERP arena since 1997. They were added to the architects (i) because the concept of a focus group implies bringing together people

with various backgrounds who are able to see a phenomenon from a variety of perspectives, and (ii) because using multiple data sources ensures data triangulation [19] and helps avoid important validation problems [3].

All focus group members were known to the author, either through common membership in professional societies or through work assignments in which the author was involved with them on a professional basis between 1995 and 2004. They were selected to participate using purposive sampling, based on the author's knowledge and their typicality. They were contacted on a personal basis by the author using e-mail. Before opening the discussion, the author provided the background of this research study and presented the 10 hypotheses as a list of high-level statements put in everyday terms [17]. Focus group data was collected interactively. The type of data being collected was qualitative notes recording our group member's position. The focus group members worked in two stages. First they focused on what they experienced as commonality no matter if they represented an ERP vendor, an adopter, or an implementation partner. Second, they discussed those aspects of the ERP size and effort estimation practices deemed unique to each player. This was to ensure that the group members are not overwhelmed with a long list of inquiries at the start of the process. We also carried out follow-up member-checking activities [16, 19], that is, getting feedback on the findings from the professionals who provided the data in the first place. Their responses are summarized in the next section, in which, for each hypothesis, we present a cluster of observations that offer evidence confirming or disagreeing with this hypothesis.

\section{Clusters of Results}

This section links the observations from our empirical study to the 10 hypotheses from [6].

Hypothesis 1: ERP vendors and adopters work together to identify, model, and assess cost factors contributing to the ERP return-on-investment equation. Observations: ERP vendors provide to clients' organizations reusable project plans and resource estimates [5]. Published experience reports suggest that these reusable artifacts are created by leveraging large datasets of past projects which ERP vendors carried out at their clients' sites and analyzed per business sector. However, our focus group suggests that the reusable project plans and estimates include, at best, only a partial view of the total ERP costs incurred to ERP adopters. Ten out of 14 members indicate that ERP adopting organizations do not directly provide any project cost data to ERP vendors because of confidentiality concerns. Instead, these members 


\section{Preliminary Results in a Multi-site Empirical Study on Cross-organizational ERP Size}

and Effort Estimation

identified the implementation partners of each ERP vendor to be the true suppliers of this data. They also indicated that, what an ERP partner reported to the ERP vendor was the project actuals expressed in "billable consulting staff-hours". These were collected during the consulting interventions of the consultants employed by the ERP implementation company. Therefore, the focus group admitted this process of project data reporting to reflect solely the perspective of the ERP consulting companies; that is, the project resources employed on the ERP adopter's side were not included. Next, all the six architects from ERP adopting organizations were united on the observation that ERP adopters never relied entirely on the reusable ERP plans provided by ERP vendors. Instead, in their experience, ERP adopters always tried to adjust the reusable plans and estimates based on "what they knew" at the pre-requirements and requirements stages of their project. However, the architects found that adjusting reusable cost estimates took into account obvious cost drivers only, and omitted the ones which were "not so obvious", such as "internal resources required to support the project team, costs to backfill the day-to-day work of project team members, process improvement, hardware upgrades, training, and organizational change”. Last, we found that no ERP adopter had any historical database of past projects, accounting for the "not so obvious" cost drivers. None has ever worked with external consultants on formulating a cost estimation model.

One out of the six architects working for ERP adopters suggested that person-hours were recorded according to a corporate-wide data collection procedure for ERP projects. The others witnessed ERP project data treated no differently from other capital (IT and non-IT) project data, which meant that project information was collected regardless of its relevance to the project context.

Two group members out of 14 said that their organizations tailored the ERP project to the resources that they were prepared to commit to the project. When these ERP adopters were unable or unwilling to commit this level of resources, the project was scaled down accordingly and the time scale extended. Tree other members witnessed ERP adopters building up their centers for ERP excellence who were given the responsibility for ERP project reporting and tracking. These centers had toolsupported data collection procedures for each ERP project type they handled, namely, new implementations, upgrades, system instance consolidations. They used the datasets of past projects of each type for judging the amount of person-hours needed for future projects of this type. Their projected estimates, however, were never reported to consultants, but did serve as input to cost negotiations with ERP implementation partners. The latter were receptive to the ERP adopter's cost projections and adjusted their numbers. Four out of 14 group members found that ERP adopters, generally, live with whatever estimates they receive from their external consultants.

Hypothesis 2: ERP vendors, consultants and adopters are currently applying the cost estimation paradigm in which cost is relative to size of the solution built. Observations: All four architects from ERP implementation consulting firms pointed out that for each new project they first looked on how much of an ERP module it would get implemented and then, they defined how many billable staff-hours seemed to be enough for carrying out the implementation tasks. They base their early estimation on their firms' knowledge of (i) the skills of the specific consultant and (ii) 
his/her past performance in implementing the specific module in which he/she is a specialist. However, the consultant's past experience is rarely collected within one business sector and in organizations of the same size and culture. The fact that in each project, consultant's performance varies due to context factors in the ERP adopting organization (e.g. ERP adopter's culture, business priorities, amount of customization) is, by and large, ignored in the estimate. Moreover, the focus group was divided on what the term 'size' means. Seven members saw size as the attribute of the tasks it would take to implement a ERP solution. They saw costs as a result of a work-breakdown-structure-based process for estimating the total effort needed for executing these tasks. Five focus group members saw size as the attribute of the user community to be served. They calculated cost by multiplying the number of users by the dollar value per user. For example, SAP, PeopleSoft, and Oracle are known among architects to cost $\$ 80,000$ per user, while BaaN and JDE, are estimated for $\$ 40,000$ per user. They also added a one-time capital cost of the software which varied enormously - from about US\$10,000 to as much as US\$60,000 per seat/user license, depending on the complexity of the software, the size of the company, and the software and the database license fee. Only two out of 14 focus group members saw size as the attribute of ERP functionality. Both, however, saw functional size as a key driver in cost estimation. Both used some versions of FPA specifically adapted for their package contexts. These two versions, though, took different types of project deliverables (in addition to the requirements) as inputs into the sizing process. The two versions interpreted the standard FSM model [11] differently in terms of what to count and how to cont it. In both, FP data were coupled with rules of thumb, for example "a project team of three people is necessary for companies with up to 300 employees" and "one more project team member is needed for every 200 employees".

Hypothesis 3: ERP adopters treat the cost for ERP solutions as the cost of doing business; as such, ERP project budgets are approved without much up-front thinking. Observations: The important implication of this proposition is that ERP cost numbers would be accepted no matter how big or precise they are. Two out of 14 focus group members confirmed that ERP project costs were considered as the price of doing business in their markets. The other two saw ERP costs as the price for doing business differently. "All our key competitors have it; we can not afford to lag behind” was a recurrent comment focus group members shared. They attributed this attitude due to the fact that an ERP is as much a strategy as a software system, which assists with the development of information strategies. That is, getting the system in is the cost which the ERP adopter pays for having the potential to develop these strategies. Our group members witnessed too many times, when CIOs who were "so in awe of the whole ERP concept that they want to implement it", no matter how much it costs or how little of a return-on-investment it delivers. Four ERP adopters got involved in what we call the "ERP sales trap", that is, they let their ERP implementation partners convince them that the cost would not be as high as they might think. Five architects also experienced that their project teams just didn't know any better and they overlooked costs.

Hypothesis 4: Business case analysis is the most common analysis ERP adopters are doing. Observations: Business cases are about assessing cost versus benefits before initiating a project. The focus group members confirmed that "making the business case is the only ritual none can skip". Their stand was that cost estimation 


\section{Preliminary Results in a Multi-site Empirical Study on Cross-organizational ERP Size}

and Effort Estimation

discussions on cross-organizational ERP should always be put in context of benefits realization. They argued that (i) ERP cost should be seen in the light of how a shared ERP solution was managed in the long run, and that (ii) how it was managed generated benefits and advantage, not just the fact that a shared ERP system existed. Though, they remained divided on what cost and benefits the business case analysis should include. In their practice, technology made a company more efficient and this was supposed to ultimately result in an overall headcount reduction. However, they pointed out that there were costs associated with reducing staff, such as severance and business reengineering costs. They indicated that, even though they saw long-term benefits associated with making employees more efficient and effective as a result of the new system, there was a short-term decrease in efficiency as employees were learning on the jobs. Though, an ERP adopter may or may not quantify these cost aspects in their business case.

An unexpected and interesting finding from our focus group discussion was that 11 out of 14 members were involved in business case analysis for "free" ERP systems. They indicated 17 ERP systems available for free to organizations. Despite their costs seemed to be zero, the most important question architects faced was whether it made sense to implement one of these systems. They said, ERP systems were deemed mission-critical to any business and no organization wanted to take any chances with relatively unknown developers or systems that might require a lot of fine-tuning to work for them. Their business cases found that the expensive effort to get these "free" systems up and running made them pricier than the systems which could be purchases/licensed or rented. However, because no architect had any "free ERP" project experience, they were concerned that their cost estimates could be exaggerated.

Hypothesis 5: For ERP adopters, business case analysis is a one-time exercise. Observations: Ten out of 14 members witnessed business case analysis happening at the project start only. They indicated the business case was used for nothing more than just convincing top management to approve the project. Their organizations justified this with the fact that in alternative ERP solutions, there was very little to distinguish feature-wise.

Hypothesis 6: Ongoing business case analysis is more effective than a one-time analysis at the project start. Observations: Four out of 14 members kept doing business case analysis at each stage of the project. All four attributed this to the higher level of maturity and "project-cost-and-benefits- consciousness" of their employers. They argued that this was, indeed, an analysis and not a justification, because they used it in a "gating process" to decide to abandon or re-scope the project, should the business case analysis was unfavorable. They also re-visited the analysis after project completion to ensure they cashed all the benefits. Two of the four members used the ongoing business case analysis to identify and manage operational business benefits and key performance indicators during and after the implementation. For example, ongoing analysis clarified costs and benefits associated with getting the accuracy of bill of material and inventory records above the $98 \%$, which was vital to get meaningful data from the ERP system. The analysis revealed that for inventory records, the cost of cycle counting turned out to be on-going. In 
contrast, once the process for maintaining the bills of material has been established, bills of material remained accurate without any significant on-going cost.

Hypothesis 7: Cost is driven by those requirements that are unknown at the stage of requirements. Observations: Our findings supported this. The focus group traced most of what they labeled "unknown" back to the amount of business change the project instilled in the adopting organizations. They indicated that cross-organizational ERP favors ERP instance consolidation projects and this implies much business change. They argued that these ERP adopters initiated their ERP implementations under duress for $\mathrm{Y} 2 \mathrm{~K}$ reasons and they had no time to optimize business process when it was implemented, and are now ready to get it right now. These focus group members found that achieving cross-organizational business process integration did not require replacement of their ERP but it usually called for adding "last mile functionality or third party software”. As typical examples were given any master data management (MDM) solution or any search tool (such as the Google Search Appliance) for finding information in cross-organizational ERP system(s). In each of these cases, ERP adopters screened different solution options, each one incurring different costs to their projects. Though, ERP adopters indicated that these costs were unknown until later project stages. For example, MDM refers to solving the problem of different systems used to store and maintain master data such as customer or supplier information. This could be a huge problem for larger cross-organizational projects that used multiple ERP systems but it was only in the configuration stage, when the true scope of this problem revealed.

Hypothesis 8: ERP sizing is done based on the business requirement document. Observations: Our findings confirm that business requirements serve as the key input into cost estimation. However, the experiences of the focus group members varied in terms of what they called "adequate requirements" and how much detail was included in their business requirement documents. ERP vendors' representatives argued that detailed process and data models should be the first to refer to, when estimating size, and later, effort. These models "were supposed to customize" the work breakdown structure in the standard reusable project plan and estimates provided by the ERP vendor. Consulting companies' and ERP adopters' representatives were firm that using the process and data requirements models would render the sizing process inefficient and expensive because estimation analysts at adopters' sites are not educated on the use of package-specific process modeling and data modeling languages. To set up a meaningful FSM process, these analysts depended on the availability of experts able to read and interpret the process and data diagrams that describe the ERP solution.

Hypothesis 9: The diversity of customization options is a key cost driver. Observations: 11 out of 14 group members suggest that customization need not be the big problem that it used to be. In their experience, modern systems let one make changes to system's screens outside of source code so that there is no need to redo them when system upgrades are released. Data reporting should also not be a problem using a report writing tool such as Crystal Reports. The focus group was united on that the configuration staff may add new fields but would rarely change any existing fields. They indicated, there was no reason for reports not to work when upgrades were provided as the tables and fields remained the same. Next, the focus group agreed on the fact that every conscious step should be made to resist the temptation to 


\section{Preliminary Results in a Multi-site Empirical Study on Cross-organizational ERP Size}

and Effort Estimation

customize the package, and that there may have to be some changes which should be allowed for. They also shared the view that some packages (e.g. SAP R/3 and JDE's EnterpriseOne) may be cheaper for the software but much pricier to configure. In their experience, SAP R/3, for instance, may only cost US $\$ 4,500$ for the software per user license but US\$20,000 per user license for consultants to configure. An unexpected insight came from 11 out of 14 members who suggested that customization is a "big problem" when an adopter is forced to migrate to another release or a package. In this case, "ERP adopters are left at the mercy of the vendor's choice on a version of a system". They meant it when either an ERP vendor discontinues a piece of functionality in a new release or when a module may be retired due to mergers between ERP vendors. In the latter case, the ERP adopter may well undergo a migration to an ERP suite they purposely did not choose in the first place, which means forcing the adopter "to expend vast amounts of money on customizing an unfamiliar package and on re-training staff, while placing their core business processes at risk".

Hypothesis 10: Knowledge management is a key driver in cross-organizational ERP projects. Observations: Ten out of 14 members confirmed that including knowledge transfer as a specific deliverable in the contract with an ERP consulting firm or other external resources could be challenging, but improved the probability of success. In cross-organizational settings, "the rapid syndication of the enterprise process logic, information assets and collaborative subsystems requires mastery in knowledge transfer to be effective and competitive”. The focus group members thought that robust knowledge transfer processes deliver rapid assimilation, improved competitiveness and high performance of all ERP stakeholders and the entire crossorganizational ERP systems portfolio. Therefore, they suggested this be a critical factor in ERP deployment, use and maintenance. Both ERP adopters and consultant's representative argued that for effective knowledge transfer, external resources must be co-located with internal resources. The two ERP practice analysts witnessed successful ERP efforts set up a "war room", that is, a large, shared space where all resources work. That enabled a "next bench" sharing practice while ensuring a productive, collaborative work and learning environment. However, this was not found to come cheaply.

Furthermore, the architects raised the concern that ERP projects should explicitly incorporate the costs of tools instrumental to "ERP knowledge diffusion", like document management systems and other leading collaborative technologies providing full, seamless access to all ERP stakeholders, particularly external consultants. Focus group members varied in terms of what "new" knowledge ERP adopters and consultants required in a dynamic cross-organizational ERP environment, how adopters can better "retain" knowledge during ERP implementation, what respective roles adopters, consultants, and ERP vendors can play in capturing, transferring and managing this knowledge, and what cost levels are associated to this. 


\section{Validation Threats}

At this early stage of our study, we could address some validity threats by offering a preliminary assessment only. We did approach two validity issues that can call into doubt the results of our preliminary study or the conclusions from our results. This was done by applying the process described in [21] that suggests researchers focus on two types of validity threats: First, the major threat to external validity arises from the fact that the ERP projects in which the architects were participating, might not be representative for the entire population of cross-organizational ERP projects. Despite the fact that the professionals were chosen based on their typicality (see Section 3), we believe that the size-and-efforts estimation practices, which these architects witnessed in their project settings, may well be just a fraction of what is observable in real life. We plan a replication study in the Netherlands to bring us to a more exhaustive and a more detailed list of how ERP adopters, vendors and consultants use FSM and effort estimation model and integrate them into larger decision-making processes. Moreover, we are interested in learning from practitioners "how common is common" and in which project context. That is, we would like to gain understanding of those size and effort estimation practices that are specific to new projects, to ERP updates, and to ERP instance consolidation projects.

Second, the key threat to the internal validity is concerned with any "alternative explanations" for the observations on the size and effort estimation practices. That is to say that while analyzing the observations, the practices that all focus group members found to be common, were specific and the final agreement on the commonality was only due to coincidental factors. To make sure we have evidence that what ERP adopters and consultants observed as common was also identifiable by external analysts, we included some representatives of ERP market research companies. This validity aspect is included in our future analysis of the focus group's transcripts and observations.

\section{Conclusions and Future Research Plans}

This paper presents preliminary clusters of observations used to build up the "weight of evidence" to support propositions from a literature survey. The clusters let us conclude the following about state-of-the-art cross-organizational ERP size and effort estimation practices:

(i) if any complete information on incurred ERP project costs exists, it is most likely to be found with the ERP adopters;

(ii) size is defined as an attribute of ERP implementation tasks, business user communities, or solution functionality; the variety of definitions used by our focus group members reflects the current confusion in the FSM literature on the object "being measured" (that is, what to count and how to count it).

(iii) whenever used, functional size is only one of the many cost parameters considered in ERP business case analysis, 
Preliminary Results in a Multi-site Empirical Study on Cross-organizational ERP Size

and Effort Estimation

(iv) the ratio of package-acquisition-cost versus package-customization costs is specific to each ERP package,

(v) the amount of business change and knowledge management add up to more expensive implementations.

Of course, we see these conclusions as early as our preliminary findings we used to derive them, and therefore, are subjected to further validation studies. As our immediate step, we plan to use sophisticated software tool-supported data analysis techniques (like coding) that will help us trace conclusions to focus group members' statements.

Second, our preliminary results indicate that the size and effort estimation topic is industry-relevant and, therefore, we also plan to replicate the focus group set up by using subjects representing the Dutch ERP market.

Third, we plan to use this study to catalogue research question that warrant future $\mathrm{PhD}$ research project efforts. At the time of writing, the author arrived at a set of 40 research questions with the help of the focus group. These remain to be grouped in areas of focus and, then, prioritized. Ongoing research is being carried out by the author and members of the COSMOS team [4] to arrive at good $[8,18,19]$ research questions.

\section{Acknowledgements}

The author thanks the professionals for volunteering their time in the focus group sessions and the anonymous reviewers for suggesting ideas on how to improve this paper. The author also thanks Janice Leschinsky for the inspirational conversations which led to a better design set-up.

\section{References}

[1] Boehm, B., C. Abts, S. Chulani, Software Development Cost Estimation Approaches - a Survey, Annals of Software Engineering, 10, 2000, pp. 177-205.

[2] Bourque, P.; Oligny, S.; Abran, A.; Fournier, B., Developing Project Duration Models in Software Engineering, Journal of Computer Science and Technology, Springer, 2006.

[3] Bratthall, L., Jorgensen M., Can You Trust a Single Data Source Explorative Software Engineering Case Study, Journal of Empirical Soft Eng, 7, 2002, pp. 9-26.

[4] Daneva, M., Status Report on Functional Size Measurement for Cross-organizational ERP Solutions: Problems and Alternative Approaches, IWSM, Potsdam, 2006, pp. 423-434.

[5] Daneva M, Wieringa R.J. A Requirements Engineering Framework for CrossOrganizational ERP Systems, Requirements Engineering Journal, 11(3), 2006, pp. 194204.

[6] Daneva, M., R.J. Wieringa, A Conceptual Framework for Research in Cross-organizational ERP Cost Estimation, Workshop on Requirements Engineering and Project Management in Software Projects, in conjunction with the 13th IEEE Requirements Engineering Conference (RE’05), Paris, 2005

[7] Davenport, T., Mission Critical: Realizing the Promise of Enterprise Systems, HBS Press, 2000.

[8] Dittrich, Y., John M., Singer, J., Tessem B., Editorial for the Special Issue on Qualitative Software Engineering Research, Journal of Inf. and Soft. Technology, 49(6), 2007, pp. 531-539.

[9] Fenton, N.E., Pfleeger, S.L., Software Metrics, A Rigorous and Practical Approach, Thomson, 2nd ed., 1996. 
[10] Gaiser, T. Conducting Online Focus Groups: a MethodologicalDiscussion. Social Science Computer Review, 15(2), 1997, pp.135-144.

[11] Garmus, D, D. Herron: Function Point Analysis: Measurement Practices for Successful Software Projects, Addison Wesley, 2001

[12] International Standard Organization (ISO), ISO/IEC 19761:2003 "Software Engineering COSMIC-FFP - A functional size measurement method".

[13] ISO/IEC IS 24570 Software Engineering - NESMA functional size measurement method version 2.1 - Definitions and counting guidelines for the application of Function Point Analysis, 2003.

[14] Jones, C. Estimating and Measuring SAP Applications with Function Point Metric, Software Productivity Research, Burlington, MA, 1998.

[15] Kivits, J. Online interviewing and the research relationship, in Hine, C. (Ed.) Virtual methods: issues in social research on the internet Oxford. Berg, 2005, pp. 35-49.

[16] Lincoln Y.S., Guba E., Naturalistic Inquiry. Thousand Oaks, CA, Sage, 1985.

[17] Orgad, S. From online to offline and back: Moving from online to offline relationships with research informants, in Hine, C. (Ed.) Virtual Methods: Issues in Social Research on the Internet, Oxford, 2005, pp. 51-65.

[18] Perry, D., A. Porter, L. Votta, Empirical Studies of Software Engineering: a Roadmap, In: Future of Software Engineering, ACM Press, 2007, pp. 345-355.

[19] Seaman C., Qualitative Methods in Empirical Software Engineering, IEEE Transaction on Soft Eng, 25(4), 1999, pp. 557-572.

[20] Stensrud E., Alternative Approaches to Effort Prediction of ERP Projects. Information \& Software Technology, 43(7), 2001, pp. 413-423.

[21] Yin, R., Case Study research: Design and Methods. Sage Publications, 2003. 